\title{
Los corpus lingüísticos en la historia del léxico: algunos datos sobre la generalización de los indigenismos antillanos en el español de España
}

\section{Linguistic Corpora in the History of Lexicon: Some Data about Generalization of Antilles Indigenous Words in Spanish}

José Luis RAMírez Luengo [joseluis.ramirezluengo@gmail.com]

Universidad Autónoma de Querétaro, México

\begin{abstract}
RESUMEN
La definición del americanismo basada exclusivamente en el uso (Company 2007: 28-9) y su consideración como un concepto eminentemente dinámico (Ramírez Luengo 2012: 398) abre perspectivas muy interesantes para el estudio histórico del léxico del español americano; entre ellas, es importante mencionar los procesos mediante los cuales un término se transforma en americanismo o deja de serlo, cuestión esta última muy poco estudiada por el momento. En esta línea, el presente trabajo pretende describir el proceso de extensión léxica que afecta a los indigenismos antillanos de origen arahuaco y tahíno y, en consecuencia, su paso de americanismos puros a voces generales por medio del ya mencionado proceso de desamericanización. Con ese propósito, se estudiará su generalización en el español de España con una metodología mixta, de carácter cuantitativo y cualitativo, que será aplicada a los datos de CORDE y por medio de la cual se procurará describir cómo se produce este proceso y en qué momento tiene lugar.
\end{abstract}

\section{Palabras Clave}

historia de la lengua; léxico; americanismo; corpus lingüístico

\begin{abstract}
A definition of americanism exclusively based on usage (Company 2007:28-9) and its consideration as a dynamic concept (Ramírez Luengo 2012:398) provide very interesting perspectives for the historical study of LatinAmerican Spanish lexicon. Among them, it is important to mention processes which produce that a word becomes americanism or it stops to be considered like this; this last issue has not been very studied until now. This paper aims to describe the process of deamericanization which makes that Antillean indigenous borrowings change from pure americanisms to general Spanish words because of their lexical spread. For this purpose, their generalization in Spain Spanish will be studied with a mixed -quantitative and qualitative- methodology that will be applied to CORDE data, in order to describe how and when this process happens.
\end{abstract}

\section{KEYWORDS}

history of the Spanish language; lexicon; americanism; linguistic corpora 
1. No cabe duda de que, dentro de los estudios desarrollados acerca del léxico que se emplea actualmente en el español de América, el análisis del concepto americanismo y de las voces que los distintos autores consideran como tales constituye una labor especialmente destacada a la que se han dedicado ya múltiples trabajos de muy distinta naturaleza (entre otros muchos, Bohórquez 1984; Buesa Oliver y Enguita Utrilla 1992; Moreno de Alba 1992; y Vaquero de Ramírez 19961); en el caso de la diacronía, sin embargo, la situación resulta parcialmente diferente, pues si bien es verdad que existen ya investigaciones que se dedican al análisis del vocabulario americano de épocas pasadas (a manera de ejemplo, Hildebrandt 1961; Mejías 1980; Frago 1999; 2010: 187-233; o Andión Herrero 2004), tampoco lo es menos que por el momento no se ha prestado la atención suficiente a los grandes procesos históricos que dotan de este valor diferencial a unidades léxicas concretas, esto es, a las líneas generales de evolución que originan los americanismos, algo especialmente sorprendente si se considera que el objetivo fundamental de la historia del español de América no es otro que describir "de qué manera -y en qué momento- se van configurando las variedades dialectales que existen hoy en tierras americanas, esto es, de qué manera y en qué momento se producen los procesos de dialectalización $n^{2 \prime}$, lo que, naturalmente, en el caso del léxico se plasma en la imposición y el empleo de "un conjunto de voces que, sean conocidas solamente en la zona o tengan un significado especial en ese lugar, constituyen un rasgo de identidad que distingue esa variedad del español de todas las demás del mundo hispánico" (Ramírez Luengo 2012: 394-395).

Quizás una de las razones que explican este hecho sea la multiplicidad de definiciones que el propio concepto americanismo presenta, lo que no solo impide obtener una visión clara de qué unidades léxicas pertenece a tal categoría ${ }^{3}$, sino que además dificulta el desarrollo de una metodología de análisis diacrónico de tales vocablos. En este sentido, no cabe duda de que la interpretación de Company (2007: 28-9) del mexicanismo -ampliable sin dificultades al americanismo- a partir del uso exclusivamente constituye un aporte fundamental por cuanto soluciona, si no todos, numerosos problemas que planteaban las definiciones previas, y aporta un criterio objetivo a la hora de determinar los elementos que se engloban dentro de esta categoría: así, si de acuerdo con la profesora mexicana el americanismo lingüístico es 'el conjunto de voces, formas o construcciones que son caracterizadoras del habla urbana, popular o culta, o ambas, de América y cuyo uso muy frecuente y cotidiano distancia la variedad americana respecto del español peninsular', se considerarán americanismos, naturalmente, cada una de las unidades que conforman el conjunto que se acaba de enunciar.

Como se ha indicado ya anteriormente (Ramírez Luengo 2015: 116), quizá lo más interesante de esta decidida apuesta por el uso como criterio único a la hora de seleccionar qué elementos forman parte de la nómina de los americanismos sea una serie de consecuencias que se derivan de ella y que se erigen como principios metodológicos de primera importancia a la hora de analizar

1 Añádanse a estos, por supuesto, los múltiples diccionarios de americanismos existentes, entre los que se pueden citar Morínigo (1998) o el DAMER (2010), por mencionar solo dos de los más conocidos y de alcance continental.

2 En este caso, se entiende la dialectalización como el 'resultado de los procesos de selección normativa que conllevan la imposición (o el rechazo) de determinados fenómenos que identifican y caracterizan geográficamente el español de una región' (Ramírez Luengo, en prensa).

3 Para una completa revisión de carácter historiográfico de las interpretaciones que se han dado a este concepto, véase el trabajo de Donadío Copello (2005: 89-92). 
de forma rigurosa este concepto en su perspectiva histórica: más allá del establecimiento de diferentes tipos de americanismos -determinados por las distintas maneras de cumplir la definición anterior: puros, semánticos y de frecuencia ${ }^{4}$-, resulta especialmente importante la constatación de la naturaleza dinámica de este concepto, que determina que "la consideración de una voz como parte de esta categoría no se mantenga necesariamente inmutable a lo largo del tiempo, sino que pueda variar a través de la historia" (Ramírez Luengo 2015: 116) de acuerdo con los procesos de extensión léxica ${ }^{5}$ que experimente y, por tanto, con las variaciones que se produzcan en su área geográfica de empleo; de este modo, la definición del americanismo que se emplea en estas páginas necesariamente implica "el carácter dinámico de este concepto y la necesidad, por tanto, de apelar a lo diacrónico para poder valorar no tanto la inclusión -atemporal y estática- de un elemento léxico a esta categoría, sino más bien su pertenencia circunstancial a ella durante una época concreta de su devenir histórico" (Ramírez Luengo 2015: 116).

Por supuesto, la aplicación de esta visión al estudio histórico del léxico americano ha permitido obtener ya una serie de resultados de cierto interés para comprender de manera más profunda la configuración de la especificidad léxica del Nuevo Mundo: por un lado, se ha determinado el momento en el que un elemento concreto, general en la época áurea, adquiere la valoración de americanismo que hoy presenta (Ramírez Luengo 2014); por otro, se ha establecido una primera taxonomía de tales elementos a partir de las distintas pautas diacrónica que les dan origen (Ramírez Luengo 2015: 119) ${ }^{6}$, lo que a su vez ha permitido postular la existencia de un punto de modificación valorativa (PMV) que se entiende como el momento en el que determinado elemento adquiere un estatus diferente al que poseía previamente, generalmente el de americanismo.

Ahora bien, resulta interesante señalar que esta visión abre también perspectivas de estudio que no solo afectan a América, sino que van más allá de este continente: en efecto, estos mismos procesos de extensión léxica -que, según se ha descrito ya, pueden originar americanismos-van a dar lugar en determinadas ocasiones al fenómeno contrario, es decir, a la desamericanización de unidades léxicas concretas o, si se quiere, a su cambio de estatus de americanismos a voces generales (Ramírez Luengo 2015: 120), algo que se produce, evidentemente, cuando tales unidades léxicas, de uso exclusivo en América en un primer momento, se divulgan y generalizan en el español de España. Por supuesto, es más que sabido que esto es lo que ocurre con muchas voces tomadas del náhuatl y especialmente con los panhispanismos de origen antillano (al estilo de chocolate y tomate entre los primeros, o canoa, huracán y maíz entre los segundos), pero lo cierto es que -más allá de ciertas noticias parciales que aporta para algunos de estos elementos Frago (2001:51-55; 2010:

4 La misma Company (2010:XVII) facilita una definición de tales tipos, de manera que los americanismos puros serán las 'voces empleadas en el español general de América inexistentes en el español peninsular general' y los americanismos semánticos, por su parte, las 'voces y construcciones formalmente compartidas con el español peninsular, pero que han desarrollado en América valores semánticos propios'; finalmente, los americanismos de frecuencia se entienden como las 'voces o construcciones compartidos, en forma y significado, con el español peninsular castellano, pero que muestran en América una mucho mayor frecuencia de empleo y de generalización', y constituyen el grupo más conflictivo y difícil de establecer a la hora de analizar históricamente el léxico.

5 Entiéndase extensión léxica en este caso como 'todo proceso (histórico) de modificación en la distribución geográfica de una voz', sea de expansión (generalización) o de reducción (dialectalización)' (Ramírez Luengo 2014: 4).

6 En concreto, se postula la existencia de americanismos no determinados diacrónicamente (AND) y americanismos determinados diacrónicamente (ADD), que a su vez se dividen en $A D D$ por pérdida léxica (relativa/absoluta) y ADD por alteración semántica (americana/española/doble) (Ramírez Luengo 2015: 118); véase este trabajo para la definición y ejemplificación de cada uno de los tipos mencionados. 
187) - se trata de un fenómeno muy escasamente estudiado y al que por el momento no se ha concedido la atención que sin duda merece, algo sorprendente si se considera que un conocimiento más extenso de este asunto puede facilitar claves de interés para la mejor comprensión de algunas de las transformaciones de peso que afectan históricamente al léxico del español.

2. En esta línea, el presente trabajo pretende describir, desde los presupuestos teóricos ya señalados, el proceso de extensión léxica que afecta a algunos indigenismos antillanos y, en consecuencia, su paso de americanismos puros a voces generales por medio del ya mencionado proceso de desamericanización. Con este propósito, se va a analizar su generalización en el español de España a partir de la indagación en corpus lingüísticos de gran amplitud -en concreto, en el Corpus Diacrónico del Español (CORDE)- con una metodología de carácter eminentemente cuantitativo, por medio de la cual se procurará describir cómo se produce este fenómeno y responder a diferentes cuestiones, tales como el momento en que tiene lugar, las semejanzas y diferencias en el proceso que muestran las distintas voces, si se descubre el mismo PMV para todos estos indigenismos o -en la medida de lo posible- los diversos factores que pueden evidenciar este cambio de valoración en el español de España, por mencionar solo algunos aspectos.

Para este primer estudio se ha optado por seleccionar únicamente cuatro unidades léxicas, a saber, canoa, hamaca, huracán y maíz; como es más que sabido, se trata de cuatro voces de origen taíno (DRAE-2014: s.v. canoa, hamaca, huracán, maíz) que resultan hoy de uso habitual en el español de España -tal y como demuestra su aparición relativamente frecuente en esta variedad, a la luz de los datos del $C R E A^{7}$ - y que, dado su empleo en todas las variedades del idioma, no pertenecen a la categoría de americanismo tal y como se ha definido en estas páginas, sino que se integran en el acervo común del léxico dialectalmente no marcado ${ }^{8}$. Por tanto, partiendo de su origen y, por lógica, su primitivo uso exclusiva o eminentemente americano, el objetivo fundamental de este estudio es analizar con cierto detenimiento cuándo y de qué manera este grupo de vocablos pierde su valoración de americanismos, para poder describir así su paso -si se permite la imagendesde la periferia de los -ismos al centro que constituye el léxico panhispánico.

3. Una primera constatación que se descubre con una simple búsqueda de los términos ya mencionados en $C O R D E^{9}$ es que, como era de esperar, todos ellos hacen acto de presencia en la

7 En concreto, los datos extraídos del corpus (consulta: 12/03/2015) son los siguientes: canoa, 66 casos; hamaca, 128 casos; huracán, 274 casos; y maíz, 857 casos (0.77, 1.49, 3.20 y 10.01 apariciones por millón de palabras respectivamente). Cabe mencionar que en todas las ocasiones se descubren ejemplos tanto en lo escrito como en lo oral.

8 Esta idea se ve corroborada por dos constataciones más: por un lado, por el hecho de que el DRAE (2014: s.v. canoa, hamaca, huracán, maíz) no marque diatópicamente ninguna de las cuatro voces en sus acepciones primarias (en concreto, 'embarcación de remo muy estrecha, ordinariamente de una pieza, sin quilla y sin diferencia de forma entre proa y popa'; 'red alargada, gruesa y clara, por lo común de pita, la cual, asegurada por las extremidades en dos árboles, estacas o escarpias, queda pendiente en el aire, y sirve de cama y columpio'; 'viento muy impetuoso y temible que, a modo de torbellino, gira en grandes círculos'; y 'planta de la familia de las gramíneas, con el tallo grueso, de uno a tres metros de altura'), que son las que se consideran en estas páginas; por otro -pero en esta misma línea-, por su no aparición en el Diccionario de americanismos, obra en la que no se descubre huracán y que, si bien registra los otros términos, solamente considera propios de las variedades americanas vocablos derivados y significados (DAMER 2010: s.v. canoa, hamaca, maíz) que se apartan de las acepciones del DRAE señaladas más arriba.

9 En realidad, las características de CORDE y de su buscador hacen que la indagación no sea del todo sencilla, pues su falta de lematización obliga a consultar todas las posibles formas gráficas que el término en cuestión puede adoptar en un momento 
documentación americana y española desde el mismo siglo XVI, lo que en principio se puede interpretar como evidencia de que desde muy temprano estos elementos léxicos salen de América y se comienzan a usar al otro lado del Atlántico ${ }^{10}$, en una situación que, establecida ya en el Quinientos, se mantiene hasta el momento actual; naturalmente, tampoco sorprende el hecho -de nuevo, constatado desde el punto de vista cuantitativo-de que el empleo de estos términos resulte en la práctica totalidad de las ocasiones más habitual en el Nuevo Mundo, dado que las voces seleccionadas no solo tienen allí su origen, sino que además hacen referencia en principio a realidades propias de estas tierras ${ }^{11}$. Ambas cuestiones se ponen claramente de manifiesto en los datos que ofrece la tabla 1, donde se recogen tanto las apariciones totales de estos elementos en el corpus de la Real Academia como su frecuencia por millón de palabras (tabla 1):

\begin{tabular}{|l|l|l|l|l|l|}
\hline \multicolumn{2}{|l|}{ TÉRMINO } & \multicolumn{1}{c|}{ S. XVI } & \multicolumn{1}{c|}{ S. XVII } & \multicolumn{1}{c|}{ S. XVIII } & \multicolumn{1}{c|}{ S. XIX } \\
\hline \multirow{2}{*}{ Canoa } & $E s p$. & $1752(38.06)$ & $367(12.52)$ & $200(20.20)$ & $111(3.20)$ \\
\cline { 2 - 6 } & $A m$. & $289(74.49)$ & $700(108.54)$ & $566(144.72)$ & $289(33.80)$ \\
\hline \multirow{2}{*}{ Hamaca } & $E s p$. & $159(3.45)$ & $34(1.16)$ & $5(0.50)$ & $16(0.46)$ \\
\cline { 2 - 6 } & $A m$. & $58(14.95)$ & $64(9.92)$ & $52(13.29)$ & $68(7.95)$ \\
\hline \multirow{2}{*}{ Huracán } & $E s p$. & $141(3.06)$ & $94(3.20)$ & $68(6.87)$ & $540(15.60)$ \\
\cline { 2 - 7 } & $A m$. & $11(2.83)$ & $23(3.56)$ & $18(4.60)$ & $184(21.52)$ \\
\hline \multirow{2}{*}{ Maíz } & $E s p$. & $1116(24.24)$ & $568(19.38)$ & $494(49.90)$ & $329(9.50)$ \\
\cline { 2 - 7 } & $A m$. & $1561(402.38)$ & $1029(159.56)$ & $640(163.64)$ & $269(31.46)$ \\
\hline
\end{tabular}

Tabla 1: Aparición de las voces en CORDE (número total y por millón de palabras)

Ahora bien, lo cierto es que -con la excepción de huracán, donde parece descubrirse una progresión en el empleo, y tanto en España como en América- los datos se muestran erráticos y sin duda poco claros, de manera que, en aras de su mejor interpretación, parece preferible aportar los porcentajes de uso normalizados que se descubren en los subcorpus textuales procedentes de cada uno de los continentes ${ }^{12}$, tal y como se recoge en la tabla siguiente (tabla 2):

concreto; a este respecto -y por lo que se refiere a las unidades léxicas consideradas para este estudio-, el caso de canoa resulta muy sencillo, pues solo es necesario llevar a cabo cuatro consultas (con/sin mayúscula; singular/plural), pero la situación se complica en el resto de vocablos, donde las posibles grafías son mucho más variadas: así, son 16 las posibilidades de hamaca (con/sin mayúscula; singular/plural; con inicial $\langle\mathrm{h}\rangle,\langle 0\rangle,\langle\mathrm{x}\rangle \mathrm{y}\langle\mathrm{j}\rangle$ ), 24 las que plantea maíz (donde se consultó solo el singular, a lo que se añaden las siguientes grafías: con/sin mayúscula; con/sin tilde; con/sin $\langle$ h $>$ intercalada; con final $\langle\mathrm{z}\rangle,\langle\mathrm{s}\rangle \mathrm{y}\langle\mathrm{c}\rangle$ ) y 30 las de huracán (con/sin mayúscula; singular/plural; con/sin tilde en singular; con inicial $<\mathrm{h}>,\langle\mathrm{u}\rangle,\langle\mathrm{j}\rangle,\langle\mathrm{x}\rangle \mathrm{y}<\mathrm{f}\rangle$ ).

10 Algo que, de hecho, es así, si bien posteriormente se demostrará que es necesario matizar -al menos de forma parcial- esta idea

11 La única excepción a este hecho lo constituye el término huracán, que -como se demostrará posteriormente- presenta claras divergencias respecto a las otras voces estudiadas.

12 La necesidad de establecer tales porcentajes normalizados responde al hecho de que CORDE presenta una notable disparidad en la cantidad de textos desde el punto de vista diatópico - con una presencia muy reducida de los de origen americano en comparación con los españoles: un 7.78 \% en el siglo XVI, un $18.03 \%$ en el siglo XVII, un $28.32 \%$ en el siglo XVIII y un $19.81 \%$ en el siglo XIX-, lo que impide llevar a cabo comparaciones fiables si no se obtienen en primer lugar los ya mencionados porcentajes normalizados de uso para cada uno de los subcorpus (España/América), que resultan, así, plenamente cotejables. 


\begin{tabular}{|l|l|l|l|l|l|}
\hline \multicolumn{2}{l|}{ TÉRMINO } & \multicolumn{1}{|c|}{ S. XVI } & \multicolumn{1}{c|}{ S. XVII } & \multicolumn{1}{c|}{ S. XVIII } & \multicolumn{1}{c|}{ S. XIX } \\
\hline \multirow{2}{*}{ Canoa } & Esp. & $33.83 \%$ & $10.33 \%$ & $12.25 \%$ & $8.66 \%$ \\
\cline { 2 - 6 } & $A m$. & $66.16 \%$ & $89.66 \%$ & $87.74 \%$ & $91.33 \%$ \\
\hline \multirow{2}{*}{ Hamaca } & Esp. & $18.78 \%$ & $10.46 \%$ & $3.65 \%$ & $5.48 \%$ \\
\cline { 2 - 6 } & $A m$. & $81.21 \%$ & $89.53 \%$ & $96.34 \%$ & $94.51 \%$ \\
\hline \multirow{2}{*}{ Huracán } & Esp. & $51.95 \%$ & $47.33 \%$ & $59.88 \%$ & $42.02 \%$ \\
\cline { 2 - 6 } & $A m$. & $48.04 \%$ & $52.66 \%$ & $40.11 \%$ & $57.97 \%$ \\
\hline \multirow{2}{*}{ Maíz } & Esp. & $5.68 \%$ & $10.82 \%$ & $23.36 \%$ & $23.30 \%$ \\
\cline { 2 - 6 } & $A m$. & $94.31 \%$ & $89.17 \%$ & $76.63 \%$ & $76.79 \%$ \\
\hline
\end{tabular}

Tabla 2: Aparición de las voces en CORDE (porcentaje normalizado)

Estos primeros datos de uso permiten descubrir ya una diferencia fundamental entre los cuatro elementos que se están estudiando: en efecto, dejando por el momento de lado las cifras del siglo XVI -que, según se dirá después, son el resultado de las características un tanto especiales que muestra el subcorpus español de CORDE en esta centuria-, salta a la vista que, mientras que canoa y hamaca presentan en España a lo largo de todo el periodo estudiado un empleo muy bajo, huracán, por el contrario, resulta de uso habitual en esta variedad desde el mismo siglo XVII, con porcentajes que se mueven en torno al $50 \%$, y maíz adquiere frecuencias de empleo de importancia a partir del siglo XVIII, cuando pasa del $10.82 \%$ al $23.36 \%$. Se puede postular, por tanto una generalización rápida de huracán y quizá un poco más tardía de maíz en esta variedad, así como una utilización claramente restringida de los otros dos elementos hasta por lo menos las postrimerías del siglo XIX, lo que quizá se pueda entender como indicio de la desamericanización de los dos primeros entre 1600 y 1800 y, por el contrario, el mantenimiento del carácter de americanismo de estos dos últimos hasta fechas mucho más recientes.

Esta hipótesis se ve corroborada, por otro lado, por medio del análisis detallado del subcorpus correspondiente a España en CORDE, en el que es posible distinguir dos tipos de obras muy concretas: por un lado, aquellas que tienen una temática claramente americana, al estilo de la Historia natural de las Indias (F. López de Gómara, 1554), la Historia del Nuevo Mundo (B. Cobo, 1653), las Noticias americanas (A. de Ulloa, 1772) o la Excursión por las Repúblicas del Plata (F. Carrasco y Guisasola, 1879) ${ }^{13}$; por otro, las que no guardan relación con América, tales como la Crónica del Emperador Carlos V (A. de Santa Cruz, 1550), El Divino Cazador (P. Calderón de la Barca, 1642), Fray Gerundio de Campazas (J. F. Isla, 1758) o Tristana (B. Pérez Galdós, 1892). Partiendo de tal oposición, los datos porcentuales de empleo de los vocablos que se están analizando en las obras de temática no americana son los siguientes (tabla 3):

13 Estas obras resultan especialmente frecuentes en el corpus del siglo XVI, y este hecho explica los porcentajes inusualmente elevados de los indigenismos estudiados en esta centuria, dado que -como se demostrará a continuación- la práctica totalidad de sus apariciones se concentran en los textos pertenecientes a esta categoría. 


\begin{tabular}{|l|l|l|l|l|}
\hline SIGLO & \multicolumn{1}{|c|}{ Canoa } & \multicolumn{1}{c|}{ Hamaca } & \multicolumn{1}{c|}{ Huracán } & \multicolumn{1}{c|}{ Maíz } \\
\hline S. XVI & $57(0.58 \%)$ & $9(1.03 \%)$ & $20(2.80 \%)$ & $34(0.54 \%)$ \\
\hline S. XVII & $48(1.39 \%)$ & $8(2.80 \%)$ & $88(57.88 \%)$ & $18(0.30 \%)$ \\
\hline S. XVIII & $42(2.52 \%)$ & $1(2.36 \%)$ & $60(42.18 \%)$ & $336(17.14 \%)$ \\
\hline S. XIX & $35(1.07 \%)$ & $12(6.62 \%)$ & $530(55.61 \%)$ & $227(4.99 \%)$ \\
\hline
\end{tabular}

Tabla 3: Aparición de las voces en el corpus de temática no americana (España-CORDE) (número total y porcentaje normalizado)

Así pues, a la luz de estos datos es posible extraer dos conclusiones de cierta relevancia para comprender mejor el empleo y la expansión de estos elementos en el español europeo de estas centurias: por un lado, los bajísimos porcentajes del siglo XVI evidencian que el supuesto conocimiento temprano de estos vocablos en la Península Ibérica que se ha defendido en ocasiones (Buesa Oliver y Enguita Utrilla 1992: 47-48; Ramírez Luengo 2007: 77) parece ser un espejismo resultado de la predominante atención prestada por los estudiosos a las obras de esta época que abordan temáticas americanas; por otro, los datos demuestran que, en consonancia con lo que se planteaba más arriba, no todas las voces ofrecen una progresión semejante en su uso, de manera que, mientras que canoa resulta claramente minoritaria durante todo el periodo considerado -en ningún caso alcanza el 3 \%-, huracán es ya de empleo habitual a partir del siglo XVII, y maíz y hamaca, aunque no de forma tan evidente, se comienzan a generalizar durante la Centuria Ilustrada y quizás el siglo XIX respectivamente ${ }^{14}$.

Volviendo, por tanto, a la cuestión básica que se persigue con este trabajo, estos acercamientos cuantitativos que se han llevado a cabo hasta el momento permiten sostener que, a pesar de sus más de 1700 ejemplos en escritos españoles del Quinientos y sus abundantes apariciones durante los siglos XVII, XVIII y XIX, canoa probablemente no es todavía en este periodo una palabra propia de la variedad empleada en España, pues su empleo circunscrito en la práctica totalidad de las ocasiones a un contexto muy específico -en concreto, a obras vinculadas con el Nuevo Mundo que son producto de hablantes relacionados de alguna forma con este continente- demuestra que, como bien señala Frago (2010: 187), “su conocimiento seguramente era de carácter libresco, detalle erudito propio de las minorías más cultivadas” o por lo menos de aquellas que por alguna circunstancia tienen contacto con las tierras americanas ${ }^{15}$; muy otra es, sin embargo, la situación de huracán, que de un escasísimo $2.80 \%$ en temáticas no americanas en el siglo XVI pasa a porcentajes de en torno

14 Para estos dos últimos términos los datos no son tan elocuentes como para canoa y huracán: en el caso de maíz, salta a la vista el avance importante en el uso que se descubre en contextos no americanos en el siglo XVIII, y si los datos del Ochocientos parecen mostrar una regresión, este hecho es consecuencia de la presencia en el corpus de los Apuntamientos para la Historia Natural de los páxaros del Paragüay y Río de la Plata (1802-1805), de Félix de Azara, donde esta voz se repite en más de 40 ocasiones; por su parte, hamaca triplica su frecuencia de uso en el siglo XIX respecto a las épocas anteriores, pero lo cierto es que se trata de números aún tan bajos que resulta difícil determinar si este aumento se debe al azar o, por el contrario, es ya el inicio del proceso que llevará a su generalización en el español de España.

15 Curiosamente, el profesor zaragozano hace este aserto al hablar del empleo de huracán en el siglo XVIII, y añade que "el arraigo de huracán en el español hablado de la época en el conjunto peninsular puede descartarse, pues muy avanzado el siglo XIX todavía sería su uso genuina y privativamente americano, o casi” (Frago 2010: 187); los datos de CORDE que se exponen en estas páginas, sin embargo, no parecen avalar tal afirmación. 
al $50 \%$ en las centurias siguientes, lo que se puede interpretar como una generalización de esta voz en España a partir del siglo XVII y, de acuerdo con el marco teórico establecido en estas páginas, muy probablemente permite fijar su desamericanización -es decir, su abandono de la categoría de americanismo- y su PMV en este momento concreto.

Como complemento a lo anterior, una indagación en los contenidos de los textos donde se registran las voces seleccionadas entre los siglos XVI y XIX puede ser también de interés para reforzar la idea de su distinta cronología de generalización en España ${ }^{16}$ : en efecto, mientras que en el siglo XVI se descubre un escenario muy similar, en el que la práctica totalidad de las apariciones de estos cuatro vocablos se concentran en dos temas concretos, ciencia/técnica e historia y documentos ${ }^{17}$-en concreto, el $92.91 \%$ de canoa, el $93.70 \%$ de hamaca, $84.83 \%$ de huracán y 96.50 \% de maíz-, la situación comienza a diversificarse a partir de este momento, en el que, una vez más, huracán pasa a utilizarse de forma más repartida en las diferentes temáticas y -lo que es más interesantes- en géneros y contenidos tan variados como la religión, la prensa, la lírica o la dramática, en un proceso de expansión que también experimenta maíz en el siglo XVIII y muy especialmente en la centuria siguiente; una vez más, canoa y hamaca se muestran más rezagados a este respecto, no solo porque a lo largo de todos los siglos analizados no se descubre un claro aumento de las temáticas en que estos términos se utilizan ${ }^{18}$, sino también porque sus empleos se siguen concentrando en algunos específicos como sociedad o historia $y$ documentos y no manifiestan, por tanto, la flexibilidad de las otras voces ya mencionadas ${ }^{19}$.

Así pues, si la expansión de los vocablos analizados desde el punto de vista porcentual y temático en el español de España se puede considerar un indicio de su generalización en esta variedad -y, por tanto, de su proceso de cambio de estatus, de americanismos a voces generales-, salta a la vista que tal proceso tiene lugar de distinta manera y en distintos momentos según el término considerado, y que en ningún caso es un fenómeno propio del siglo XVI, sino de épocas posteriores. Ahora bien, no es menos evidente que una aproximación meramente cuantitativa a esta cuestión se muestra sin duda insuficiente, por cuanto resulta complicado detectar por medio de esta metodología el momento preciso en el que una unidad léxica pierde para los hablantes su valor diatópicamente marcado y se convierte en voz general (cualquier cosa que eso sea); parece necesario, por tanto, aunar a lo cuantitativo aproximaciones de tipo cualitativo que permitan explorar de forma más profunda la generalización ya indicada, y que consideren aspectos tan variados $-\mathrm{y}$ no siempre fáciles de valorar- como, entre otros, la ya mencionada

16 Para llevar a cabo este análisis se ha seguido la tipología establecida en CORDE, tanto en lo que se refiere a la taxonomía como a la pertenencia de los distintos textos a cada uno de los géneros establecidos.

17 Cuestión no del todo sorprendente, por cuanto son tales temas los que concentran la mayor parte de obras relacionadas con América, en las que -como se dijo ya- aparece en esta centuria la inmensa mayoría de las ocurrencias de estos elementos.

18 De hecho, lo que se descubre es el proceso contrario: una disminución entre el siglo XVI -cuando canoa y hamaca aparecen en ocho y cinco de los grupos establecidos por CORDE respecticamente- y el siglo XIX, en el que canoa hace su aparición en seis grupos y hamaca exclusivamente en cuatro; contrastan estos datos, según se ha dicho ya, con los que muestran huracán -ocho grupos en el siglo XVI y once en el siglo XIX- y maíz, que pasa de seis a diez ámbitos temáticos.

19 Aunque, una vez más, es posible detectar alguna diferencia incipiente entre estos dos vocablos, dado que en el caso de canoa la situación permanece prácticamente estable a lo largo de los siglos XVII al XIX -con porcentajes del 95.09 $\%, 85 \%$ y $81.97 \%$ respectivamente- y en hamaca, sin embargo, una vez más es posible apreciar un cambio de tendencia ya en el siglo XIX, dado que los porcentajes previos del $76.47 \%$ y del $80 \%$ descienden a un $50 \%$ en el Ochocientos. 
extensión de los términos a ámbitos temáticos diferentes, el momento de su incorporación a las obras lexicográficas, la presencia o ausencia de marcación diatópica en ellas ${ }^{20} \mathrm{o}$, desde otro punto de vista, la época en la que se produce en los textos la desaparición de la labor de glosa -en forma de sinonimos, definiciones, descripciones o comparación con un referente hispánico- que acompaña en sus inicios a estos vocablos y que en principio demuestra su no pertenencia a la variedad dialectal del autor del texto (Frago, en línea) (ejemplos 1, 2; ambos tomados de CORDE).

1) Ponen el cuerpo en una hamaca, que como se ha dicho es como a manera de honda colgada en el aire (B. de las Casas: Apologética historia sumaria, 1527-1550).

2) El estilo que tienen [...] es meterse en un canoa o barquilla, que es como una artesa, y bogando, llegarse al costado de la ballena (J. de Acosta: Historia natural y moral de las Indias, 1590)

4. A partir, por tanto, de todo este análisis previo, es posible extraer ya una serie de conclusiones de cierto interés que atañen no solo a la diacronía de determinados vocablos del español, sino también -y quizá más importante aún- a la metodología que se puede emplear a la hora de estudiar algunos procesos que resultan de una importancia más que notable para obtener una comprensión más completa de la evolución histórica del léxico de esta lengua.

De este modo -y en consonancia con lo defendido por Company (2007: 28-29)-, es de destacar en primer lugar la elección del uso como criterio único a la hora de definir el americanismo, cuestión que no solo evita los problemas y las dificultades que plantean otras propuestas, sino que además evidencia el carácter dinámico de este concepto, que supone que la consideración de una voz como parte de esta categoría no se mantiene "necesariamente inmutable a lo largo del tiempo, sino que pueda variar a través de la historia” (Ramírez Luengo 2015: 116); por supuesto, esta perspectiva permite estudiar aspectos tan variados como las diversas pautas diacrónicas que generan los distintos tipos de americanismo, los procesos de cambio de valoración -por americanización, pero también por desamericanización- que experimenta un determinado elemento léxico o el momento en que tal proceso tiene lugar (PMV).

En esta línea, el presente trabajo ha estudiado la desamericanización de ciertos vocablos de origen indígena antillano que diacrónicamente pasan a ser voces generales -esto es, diatópicamente no marcadas- a causa de su generalización en el español de España. Con este propósito, y a partir de los datos de CORDE, se ha analizado el empleo de estos términos durante los siglos XVI al XIX teniendo en cuenta no solo su porcentaje de aparición en ambos continentes, sino también su presencia en obras españolas de contenido americano y no americano y su extensión por géneros textuales y temáticas variadas; pues bien, todos estos análisis parciales parecen ofrecer los mismos resultados: por un lado, que -a pesar de lo que se ha mantenido en

20 A este respecto, las fechas de generalización de los cuatro indigenismos propuestas en estas páginas explicarían por qué en el caso de huracán y maíz el Diccionario de Autoridades (Real Academia Española 1979: s.v. huracán, maíz) no hace ninguna referencia a América, mientras que en canoa señala que es la "embarcación que hacen los indios" (Real Academia Española 1979: s.v. canoa) y para hamaca el DRAE en 1780 -no se recoge en Autoridades-indica que se trata de una "cama suspendida en el aire de que suelen servirse los indios" (Rel Academia Española 1780: s.v. hamaca); evidentemente, tales diferencias parecen avalar desde la lexicografía la ya mencionada generalización de huracán y maíz en los siglos XVII y XVIII y, por el contrario, el carácter todavía ajeno, relacionado con América, que presentan canoa y hamaca en esta época para los académicos españoles. 
ocasiones (Buesa Oliver y Enguita Utrilla 1992: 47-48; Ramírez Luengo 2007: 77)-, los indigenismos considerados (canoa, hamaca, huracán y maíz) constituyen en el siglo XVI voces ajenas al español de España, por cuanto en esta época su uso se concentra casi totalmente en textos relacionados con América; por otro, que la extensión posteriormente de estas voces no se va a producir a la vez, de manera que, mientras que es posible establecer el PMV de huracán en el siglo XVII y el de maíz en la Centuria Ilustrada, en el caso de hamaca quizá se deba esperar hasta el siglo XIX, e incluso a momentos posteriores en el de canoa $^{21}$.

Por otro lado, salta a la vista que, a pesar de la importancia de lo cuantitativo y de los satisfactorios resultados que ofrece esta perspectiva, el análisis de la desamericanización de estas voces y de su generalización por España exige también acercamientos de tipo cualitativo que, si bien resultan más difíciles de ponderar, sin duda han de aportar testimonios de interés para poder calibrar y valorar mejor los datos cuantitativos ya mencionados; en este sentido, la constatación de que es necesario apelar a criterios cualitativos como forma de superar las insuficiencias que se han detectado en las aproximaciones cuantitativas iniciales constituye sin duda una conclusión metodológica de primera importancia que será necesario tener muy en cuenta en posteriores análisis ${ }^{22}$.

En definitiva, resulta más que evidente que son aún muchas las tareas a las que se enfrenta el investigador interesado en estas cuestiones: es necesario, por supuesto, afinar de forma más precisa el método de trabajo ${ }^{23}$, pero también, y muy especialmente, desarrollar análisis puntuales que, a partir de estos supuestos, se centren en el estudio de vocablos de muy diversa índole, pues no cabe duda de que solo a partir de estos estudios específicos será posible conocer y seguir describiendo cómo, cuándo y de qué manera se producen las transformaciones diacrónicas que, a través de procesos tan simples en su concepción como - paradójicamente- dificultosos en su indagación histórica, han dado como resultado la distribución dialectal que muestra el léxico español en el momento actual.

21 Generalizando -en la medida de lo posible- estos resultados, no cabe duda de que tiene razón Frago (2001: 51) cuando señala que muchos de los indigenismos americanos "para la mayoría de los españoles hasta hace poco han sido términos meramente librescos y objeto de erudición".

22 Parcialmente relacionados con estos criterios cualitativos se encuentran, por supuesto, las cuestiones de índole puramente histórica, las cuales pueden aportar datos de notable relevancia para la mejor comprensión de los fenómenos que se pretenden analizar en estas páginas, en el fondo eminentemente históricos: en relación con los vocablos considerados en este estudio, no cabe duda, por ejemplo, de que el conocimiento del proceso de expansión del cultivo del maíz por España va a constituir una información de gran interés para describir de manera más profunda cuándo y de qué manera se incorpora y generaliza este indigenismo en las variedades peninsulares del español; en este sentido, un estudio como este refuerza la idea de que "la evolución lingüística es una manifestación del espíritu y vida de las comunidades hablantes" (Lapesa 1978: 18), algo que resulta especialmente evidente en el caso del vocabulario y demuestra, una vez más, la necesidad de propiciar un acercamiento interdisciplinar a la historia de la lengua en general y, más en concreto, a la del léxico.

23 Por ejemplo, será necesario introducir de alguna manera en la metodología lo diastrático, que probablemente resulte un factor de importancia para entender de forma más profunda y detallada los procesos de extensión léxica; al mismo tiempo, en este caso se ha considerado España como un todo, si bien el mismo Frago (2001: 52-54) demuestra que las diferencias geográficas respecto al uso de los indigenismos son muy notables, con una presencia mucho más marcada y temprana de estos en zonas como, por ejemplo, Andalucía o Canarias. Por supuesto, el análisis de todas estas cuestiones exigiría el empleo de un corpus que contara con una homogeneidad dialectal, sociolingüística, tipológica y temática que a día de hoy está muy lejos de ofrecer CORDE. 


\section{Referencias bibliográficas}

Andión Herrero, M. A. (2004). Los indigenismos en la 'Historia de las Indias' de Bartolomé de las Casas. Madrid: CSIC.

Asociación de Academias de la Lengua Española. (2010). Diccionario de Americanismos. Madrid: Santillana.

Bohórquez, J. G. (1984). Concepto de americanismo en la historia del español. Bogotá: Instituto Caro y Cuervo.

Buesa Oliver, T., \& Enguita Utrilla, J. M. (1992). Léxico del español de América: su elemento patrimonial e indígena. Madrid: Mapfre.

Company, C. (2007). El siglo XVIII y la identidad lingüística de México. Discurso de ingreso a la Academia Mexicana de la Lengua (10 de noviembre de 2005). México: Universidad Nacional Autónoma de México/ Academia Mexicana de la Lengua.

- (2010). Introducción. In Academia Mexicana de la Lengua. Diccionario de Mexicanismos (pp. XVXXIII). México: Siglo XXI.

Donadío Copello, M. (2005). Algo acerca de los americanismos y las regiones dialectales. In C. Aráus Puente (Coord.), Manual de lingüística hispanoamericana (t. II) (pp. 83-141). Bogotá: Instituto Caro y Cuervo.

Frago, J. A. (1999). Historia del español de América. Madrid: Gredos.

- (2001). Indigenismos y americanismos léxicos. In J. A. Frago, \& M. Franco Figueroa, El español de América (pp. 39-67). Cádiz: Universidad de Cádiz.

- (2010). El español de América en la Independencia. Santiago de Chile: Taurus.

. (1992). Estrategias para la investigación en el español americano hasta 1656. In Actas del congreso de la lengua española. Sevilla 1992. <http://cvc.cervantes.es/obref/congresos/sevilla/unidad/ponenc_gracia.htm> Hildebrandt, M. (1961). La lengua de Bolívar, I. Léxico. Caracas: Universidad Central de Venezuela.

Lapesa, R. (1978). Historia lingüística e historia general. In Buscad sus pares, pocos. Tres ensayos (pp. 13-24). Madrid: Universidad Complutense de Madrid.

Mejías, H. A. (1980). Préstamos de las lenguas indígenas en el español americano del siglo XVII. México DF: Universidad Nacional Autónoma de México.

Moreno de Alba, J. G. (1992). Diferencias léxicas entre España y América. Madrid: Mapfre.

Morínigo, M. A. (1998). Nuevo Diccionario de Americanismos e Indigenismos. Buenos Aires: Claridad.

Ramírez Luengo, J. L. (2007). Breve historia del español de América. Madrid: Arco/Libros.

- (2012). El léxico en los procesos de dialectalización del español americano. Cuadernos del Instituto de Lengua Española, 7, 393-404.

. (2014). Cómo el español de España genera americanismos: a propósito del americanismo puto 'homosexual. Lengua y habla, 18, 1-12.

. (2015). El americanismo y la historia: algunas pautas diacrónicas de creación de americanismos (léxicos). Miradas, 13, 114-123.

. (en prensa). Aspectos metodológicos para el estudio histórico del léxico americano: conceptos, ejemplificación y tareas para el futuro. Moenia, 23.

[CORDE]: Real Academia Española. Corpus diacrónico del español. <http://www.rae.es>

[CREA]: — Corpus de referencia del español actual. <http://www.rae.es $>$

- (1780). Diccionario de la lengua castellana compuesto por la Real Academia Española, reducido a un tomo para su más fácil uso. Madrid: Joachin Ibarra.

- (1979). Diccionario de Autoridades (facsímil de la edición de 1726-1739). Madrid: Gredos.

. (2014). Diccionario de la lengua española. Madrid: Espasa.

Vaquero de Ramírez, Ma. (1996). El español de América, II. Morfosintaxis y léxico. Madrid: Arco/Libros. 
